\title{
Experience with cellular and antibody mediated rejection after heart transplantation
}

\author{
Ivan Málek MD PhD ${ }^{1}$, Tomáš Gazdič MD², Markéta Hegarová MD ${ }^{1}$, Luděk Voska $M D^{3}$, \\ Libuše Pagáčová MD ${ }^{4}$, Josef Kautzner MD PhD ${ }^{1}$, Jan Pirk MD PhD²
}

\begin{abstract}
I Málek, T Gazdič, M Hegarová, et al. Experience with cellular and antibody mediated rejection after heart transplantation. Curr Res Cardiol 2015;2(2):91-93.

OBJECTIVES: To evaluate celluar and antibody mediated rejection in a group of patients after heart transplantation (HTX), performed in the authors' institution during a six-year period.

METHOD: A retrospective analysis of patients surviving $\geq 12$ months after HTX was performed. Rejection was evaluated from the samples obtained during endomyocardial biopsy, and graft function was assessed using echocardiography. The duration of follow-up ranged from 12 to 72 months.
\end{abstract}

RESULTS: In the 196 patients evaluated, 65 treated episodes of cellular rejection were recorded in 50 patients, with significant reduction on tacrolimus prophylaxis. Antibody mediated rejection occured in $5.6 \%$ of patients, and was complicated by graft dysfunction in $64 \%$.

CONCLUSION: Contemporary immunosuppressive prophylaxis decreases the frequency of cellular rejection, allowing modification of endomyocardial biopsy schedule. Antibody mediated rejection is a relatively rare but clinically important complication after HTX, and necessitates combined agressive therapy.

Key Words: Endomyocardial biopsy; Graft rejection; Heart transplantation

echocardiography performed on the same day as the biopsy. The incidence of rejection was evaluated in the entire group and during two time periods, which varied according to selection of a calcineurin inhibitor (Table 2).

CR

\section{RESULTS}

There were 65 treated episodes of CR in 50 (25.5\%) patients in the reporting period. One episode occured in 42 patients, two episodes in seven and three episodes in one. Sixty-two episodes were successfully treated with corticosteroids; in three cases, antithymocyte globulin was used. Combination with AMR was detected in two cases only. Episodes of 'pure' CR were never accompanied by the development of heart failure or graft dysfunction.

A significant reduction was observed in the incidence of CR in the second period, during which tacrolimus prophylaxis was more frequently used (Table 3).

\section{METHODS}

In the period between January 1, 2005 and December 31, 2010, HTX was performed in 247 patients. Thirteen (5.3\%) died within 30 days after the surgery, and an additional 38 (15.5\%) died during follow-up. Retrospective analysis was performed in the group of 196 patients who survived at least 12 months after HTX; follow-up lasted for 12 to 72 months. Induction prophylaxis with polyclonal antithymocyte globulin was used in all patients; the basis of long-term prophylaxis was a calcineurin inhibitor (cyclosporine A or tacrolimus), typically in combination with mycophenolate mofetil and prednisone.

Rejection was evaluated from samples obtained during endomyocardial biopsy (EMB) from the right ventricle. Banff classifications were used to assess the presence and degree of CR (Table 1) (2); furthermore, the presence of complement fragments $\mathrm{C} 3 \mathrm{~d}$ and $\mathrm{C} 4 \mathrm{~d}$ was the basis for diagnosis of AMR (Figure 1) $(3,4)$. Biopsies were performed at regular intervals ('protocolar biopsies'), and a total of 2570 sample series were reviewed. Graft function was assessed using

\section{AMR}

AMR was diagnosed in $11(5.6 \%)$ patients, and graft dysfunction developed in seven. Occurrence and treatment of this complication is presented in Table 4.

\section{DISCUSSION}

The main finding of the present study was the decline in CR, which enabled us to reduce the frequency of protocolar biopsies. Rejection after HTX occurs in several forms. Peracute rejection immediately after the operation is extremely rare; subsequently, there may be episodes of CR or AMR. Chronic rejection affects the coronary arteries and is one of the components of coronary graft disease.

For early diagnosis of rejection, EMB is necessary because noninvasive methods are not sufficiently reliable (5). Protocolar biopsies are performed at prespecified time intervals, with decreasing frequency during the time

${ }^{1}$ Cardiology Department; ${ }^{2}$ Cardiovascular Surgery Department; ${ }^{3}$ Department of Clinical and Transplant Pathology; ${ }^{4}$ Haematology Department, Institute for Clinical and Experimental Medicine, Prague, Czech Republic

Correspondence: Dr Ivan Málek, Department of Cardiology, Institute for Clinical and Experimental Medicine, Vídeňská 1958/9, 140 21 Prague 4, Czech Republic. Telephone 420-236055011, fax 420-261362986, e-mail ivma@ikem.cz 
TABLE 1

Acute cellular rejection grading according to Banff classification (2)

\begin{tabular}{lcc}
\hline & $\begin{array}{c}\text { Revised Banff } \\
(\mathbf{2 0 0 4 )}\end{array}$ & $\begin{array}{c}\text { Original Banff } \\
\mathbf{( 1 9 9 0 )}\end{array}$ \\
\hline $\begin{array}{l}\text { No rejection } \\
\begin{array}{l}\text { Focal lymphocyte infiltrates, no myocardial } \\
\text { damage }\end{array}\end{array}$ & $\begin{array}{c}\text { R R } \\
\text { Diffuse infiltrates, no myocardial } \\
\text { damage }\end{array}$ & $1 \mathrm{R}$ \\
$\begin{array}{l}\text { Lymphocyte infiltrates, maximum one } \\
\text { focus of myocyte damage }\end{array}$ & $1 \mathrm{R}$ & $1 \mathrm{~B}$ \\
$\begin{array}{l}\text { Two or more foci of infiltrate with myocyte } \\
\text { damage }\end{array}$ & 2 & 2 \\
$\begin{array}{l}\text { Diffuse infiltrates with multifocal myocyte } \\
\text { damage }\end{array}$ & $3 \mathrm{R}$ & $3 \mathrm{~A}$ \\
\begin{tabular}{l} 
As 3R + edema, hemorrhage, vasculitis \\
\hline
\end{tabular} & $3 \mathrm{R}$ & $3 \mathrm{~B}$ \\
\hline
\end{tabular}

TABLE 2

Characteristics of patients included in the present study $(n=196)$

\begin{tabular}{ll}
\hline Men/women, n/n & $156 / 40$ \\
Age, years, range & $19-74$ \\
Diagnosis, IHD/DCMP/Other & $78 / 88 / 30$
\end{tabular}

First period: January 1, 2005 - December 31, 2008

Total, $\mathrm{n}$

119

CyA/TAC, \%/\%

$64 / 36$

Second period: January 1, 2009 - December 31, 2010

Total, $\mathrm{n}$

77

CyA/TAC, \%/\%

$4 / 96$

CyA Cyclosporine A; DCMP Dilated cardiomyopathy; IHD Ischemic heart disease; TAC Tacrolimus

TABLE 3

Incidence of acute cellular rejection in the two time periods

First period: January 1, 2005 - December 31, 2008

Total, $\mathrm{n}$

119

Cellular rejection, $\mathrm{n}(\%)$

$39(32.8)$

Second period: January 1, 2009 - December 31, 2010

Total, $\mathrm{n}$

Cellular rejection, $\mathrm{n}(\%)$

$11(14.3)$

First versus second period: $P=0.004$

elapsed. According to the classical scheme still used in many centres, 12 to 13 biopsies are performed during the first year. This causes discomfort for the patient and is accompanied by additional risk for complications (6). Based on our findings, we created a new schedule. During the first year, the number of planned biopsies was reduced to eight, and additional biopsies after the first year are performed only in high-risk patients or when there is a clinical need. According to the preliminary prospective evaluation, this approach is safe (7).

Recently, attention has focused on AMR. The basis for AMR diagnosis is EMB findings, the presence of donor-specific antibodies in serum and, in most cases, graft dysfunction. Some histological changes may be present in the biopsy, but the most sensitive finding is the presence of complement fragments C3d and C4d in $>50 \%$ of vessels encountered in each sample. Thus, immunohistochemical investigation is necessary for this analysis.

According to the literature, AMR occurs during follow-up in $10 \%$ to $20 \%$ patients (8). Immunized patients - ie, those with the presence of antibodies against a lymphocyte panel before HTX and/or those who

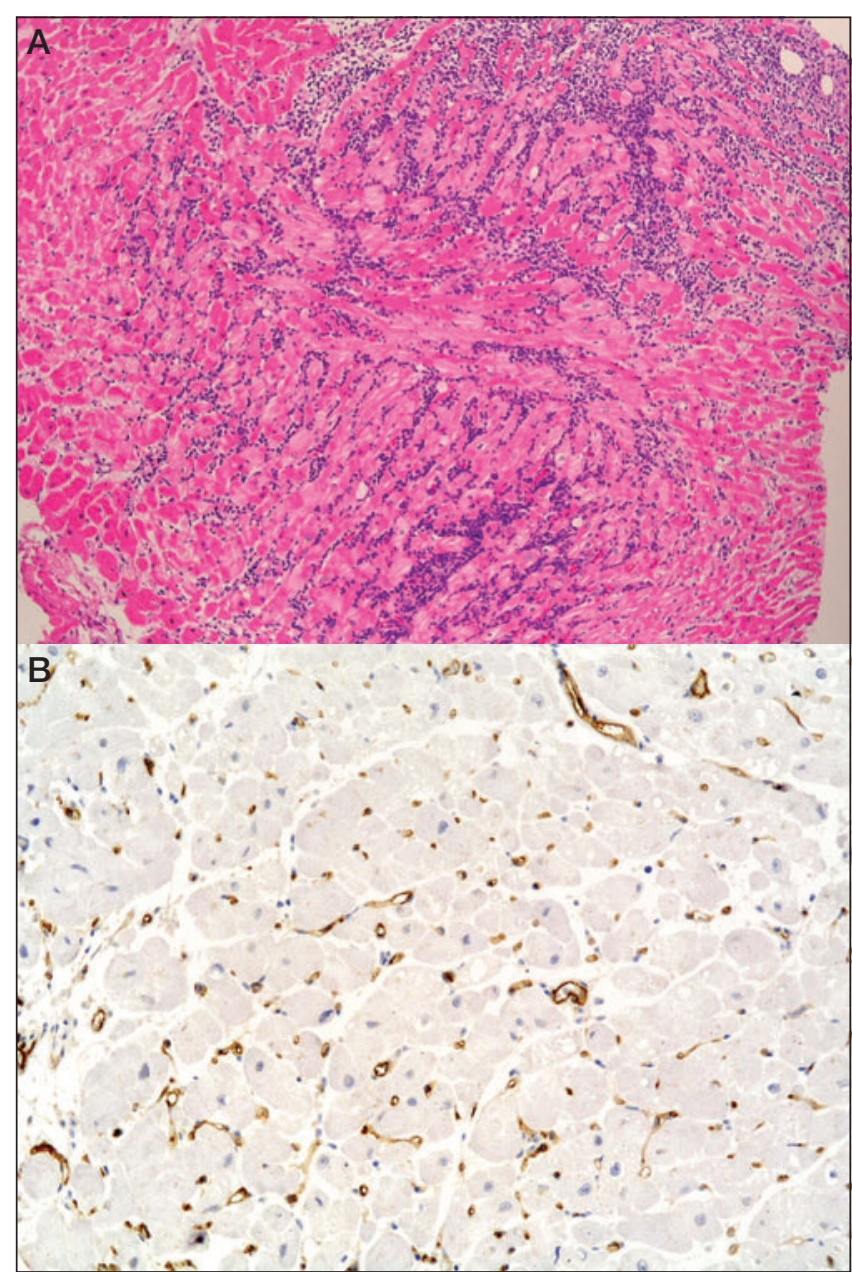

Figure 1) Photographs of cellular and antibody mediated rejection in endomyocardial biopsy samples. A Acute cellular rejection, Banff classification 2R. Lymphocyte infiltration with destruction of myocytes. Stained with hematoxylin-eosin. B Antibody mediated rejection. Diffuse positivity of C4d fragments in capillaries. Immunohistochemical staining using rabbit antihuman $\mathrm{C} 4 d$ polyclonal antibody

developed donor-specific antibodies after HTX - are at increased risk. Another risk factor is cytomegalovirus infection. AMR is a prognostically unfavourable finding that is often accompanied by immediate graft failure, and also by subsequent developement of coronary graft disease (9). In our study, AMR is reported less frequently compared with the literature. This may be explained by the fact that the development of antibodies was not systematically studied; moreover, immunohistochemical test sampling has not always been available. Therefore, we selected only clinically severe episodes or their consequences manifested as graft failure in patients with coronary vasculopathy.

Unlike the cellular form, AMR is not easily treatable. Corticosteroids or antilymphocyte antibodies are not sufficiently effective; it is necessary to eliminate the antibodies present in blood and prevent their further formation (10). The available elimination methods are plasmapheresis and immunoadsorption $(11,12)$, both of which were successfully used in our patients. The elimination is usually completed by administration of intravenous immunoglobulin, which inhibits residual antibodies. An effective way of preventing further antibodies formation is suppression of B-lymphocytes (rituximab) (13) or plasma cells (bortezomib) (14).

Table 4 presents the scenarios in which these treatment options were used. The combination therapy was well tolerated and successful in our patients. Graft dysfunction was eliminated and treated patients had good 
TABLE 4

Comprehensive data regarding antibody mediated rejection in 11 patients after heart transplantation (HTX)

\begin{tabular}{|c|c|c|c|c|c|c|c|}
\hline Sex/year of birth & $\begin{array}{c}\text { Time since HTX, } \\
\text { months }\end{array}$ & Rejection diagnosis & Cause & LV dysfunction* & Treatment & $\begin{array}{l}\text { Follow-up, } \\
\text { months }\end{array}$ & $\begin{array}{c}\text { Last control } \\
\text { (LV EF\%) }\end{array}$ \\
\hline Male/1953 & 72 & C3d, C4d, CM & Unknown & Yes & $I A, I V I G$ & 80 & 50 \\
\hline Female/1976 & 0.5 & $\mathrm{CM}$ & Unknown & Yes & MP, ATG & 74 & 60 \\
\hline Female/1963 & 0.5 & $\mathrm{C} 4 \mathrm{~d}$ & Unknown & Yes & MP & 40 & 60 \\
\hline Male/1957 & 1.5 & $\mathrm{C} 4 \mathrm{~d}, \mathrm{CM}$ & $\uparrow P R A$ & No & IA & 30 & 50 \\
\hline Female/1968 & 0.25 & C4d, DSA & $\uparrow \mathrm{PRA}, \mathrm{CM}$ & Yes & $\begin{array}{l}\text { PF, IVIG, } \\
\text { rituximab, } \\
\text { sirolimus }\end{array}$ & 21 & 55 \\
\hline Female/1944 & 0.5 & $\mathrm{C} 3, \mathrm{Cd} 4$ & $\mathrm{CM}$ & No & MP & 56 & 60 \\
\hline Female/1966 & 1 & $U$ & Unknown & No & PF, IVIG & 26 & 60 \\
\hline Male/1965 & 51 & CAV & Noncompliance & Yes & ATG & 53 & SD \\
\hline Male/1963 & 10 & CAV & Noncompliance & Yes & MP & 15 & 40 \\
\hline Male/1950 & 13 & $\mathrm{C} 4 \mathrm{~d}, \mathrm{CM}$ & $\begin{array}{c}\text { Conversion to } \\
\text { rapamycin }\end{array}$ & No & MP, ATG & 14 & 60 \\
\hline
\end{tabular}

${ }^{*}$ Ejection fraction (EF) $\leq 40 \%$. $\uparrow$ Increase; ATG Antithymocyte globulin; CM Positive cross-match test; CAV Coronary vasculopathy; DSA Donor-specific antibodies; IA Immunoadsorption; IVIG Intravenous immunoglobulin; LV Left ventricular; MP Methylprednisolone; PRA Panel-reactive antibodies; PF Plasmapheresis; SD Sudden death; U Unknown

prognosis in medium-term follow-up. Recently, we used bortezomib for the first time, which was administered in a young woman who developed high titres of donor-specific antibodies and severe AMR after HTX (15).

\section{CONCLUSION}

Retrospective analysis of a relatively large group of HTX patients confirmed that contemporary immunosuppressive prophylaxis decreases frequency of CR. This enables a modification of EMB schedule without negative consequences for the patients. AMR is a relatively rare but clinically important complication after HTX. According to our experience, intensive combination therapy is often successful even in patients developing graft dysfunction.

FUNDING: This work was supported by the research grant of the Internal Grant Agency, Ministry of Health, Czech Republic (IGA NT 11262-6).

\section{REFERENCES}

1. Stehlík J, Edwards LB, Kucheryavaya AY, et al. The registry of the International Society for Heart and Lung Transplantation: 31st official adult heart transplant report - 2012. J Heart Lung Transplant 2014:33:996-1008.

2. Stewart S, Winters GL, Fishbein MC, et al. Revision of the 1990 working formulation for the standardization of nomenclature in the diagnosis of heart rejection. J Heart Lung Transplant 2005;24:1710-20

3. Berry GJ, Angelini A, Burke MM, et al. The ISHLT working formulation for pathologic diagnosis of antibody-mediated rejection in heart transplantation: Evolution and current status (2005-2011). J Heart Lung Transplant 2011;30:601-11.

4. Gupta S, Mitchell JD, Lavingia B, et al. Utility of routine immunofluorescence staining for $\mathrm{C} 4 \mathrm{~d}$ in cardiac transplant recipients. J Heart Lung Transplant 2009;28:776-80.

5. Patel JK, Kobashigawa JA. Should we be doing routine biopsy after heart transplantation in a new era of anti-rejection? Curr Opin Cardiol 2006;21:127-31.
6. Nguyen V, Cantarovich M, Cecere R, Giannetti N. Tricuspid regurgitation after cardiac transplantation: How many biopsies are too many? J Heart Lung Transplant 2005; (7 Suppl):S227-S231.

7. Malek I, Voska L, Karmazín V, Pirk J. Validation of the new protocol of endomyocardial biopsies after cardiac transplantation. Vienna, September 8 to 11, 2013. 16th ESOT Congress. European Society for Organ Transplantation. In: 16th ESOT Congress: Abstracts (online). Edinburg: European Society for Organ Transplantation 2013, s. 1, abstract O077.

8. Michaels PJ, Espejo ML, Kobashigawa J, et al. Humoral rejection in cardiac transplantation: Risk factors, hemodynamic consequences and relationship to transplant coronary artery disease. J Heart Lung Transplant 2003;22:58-69.

9. Taylor DO, Yowell RL, Kfoury AG, et al. Allograft coronary artery disease: Clinical correlations with circulating anti-HLA antibodies and the immunohistopathologic pattern of vascular rejection. J Heart Lung Transplant 2000;19:518-21.

10. Uber WE, Self SE, Van Bakel AB, Periera NL. Acute antibody-mediated rejection following heart transplantation. Am J Transplant 2007;7:2064-74.

11. Grauhan O, Knosalla C, Ewert R, et al. Plasmapheresis and cyclophosphamide in the treatment of humoral rejection after heart transplantation. J Heart Lung Transplant 2001;20:316-21.

12. Kaczmarek I, Deutsch MA, Sadoni S, et al. Successful management of antibody-mediated cardiac allograft rejection with combined immunoadsorption and anti-CD20 monoclonal antibody treatment: Case report and literature review. J Heart Lung Transplant 2007;26:511-5

13. Garrett HE Jr, Duval-Seaman D, Helsley B, et al. Treatment of vascular rejection with rituximab in cardiac transplantation. J Heart Lung Transplant 2005;24:1337-42.

14. Woodle ES, Alloway RR, Girnita A. Proteasome inhibitor treatment of antibody-mediated allograft rejection. Curr Opin Organ Transplant 2011;16:434-8.

15. Gazdič T, Svobodova E, Kubanek M, et al. Bortezomib-containing regimen for primary treatment of early antibody-mediated cardiac allograft rejection: A case report. Prog Transplant 2015;25:1-4. 